\title{
Characterization of anatomy, lignin distribution, and response to pretreatments of sugarcane culm node and internode
}

\author{
Michel Brienzo ${ }^{a}, b, *$, Yuri Abud ${ }^{a}$, Solange Ferreira ${ }^{a}$, Roberta C.N.R Corrales ${ }^{c}$, \\ Viridiana S. Ferreira-Leitão ${ }^{c, d}$, Wanderley de Souza ${ }^{\mathrm{a}, e, f, g}$, Celso Sant'Anna ${ }^{\mathrm{a}, \mathrm{f}, \mathrm{g}}$ \\ a Laboratory of Biotechnology (Labio), Metrology Applied to Life Science Division-National Institute of Metrology, Quality and Technology (Inmetro), \\ Duque de Caxias, RJ, Brazil \\ ${ }^{\mathrm{b}}$ Laboratory of Biomass Characterization, Bioenergy Research Institute (IPBEN), São Paulo State University (UNESP), Rio Claro, SP, Brazil \\ ${ }^{\mathrm{c}}$ Laboratory of Biocatalysis, National Institute of Technology (INT), Rio de Janeiro, RJ, Brazil \\ ${ }^{\mathrm{d}}$ Federal University of Rio de Janeiro, Chemistry Institute, Department of Biochemistry, Rio de Janeiro, RJ, Brazil \\ e Laboratory of Cell Structure, Institute of Biophysics Carlos Chagas Filho, Rio de Janeiro Federal University, National Science and Technology Institute in \\ Structural Biology and Bioimaging, Rio de Janeiro, RJ, Brazil \\ ${ }^{\mathrm{f}}$ The National Institute of Science and Technology for Structural Biology and Bioimaging, Rio de Janeiro, RJ, Brazil \\ ${ }^{\mathrm{g}}$ Federal University of Rio de Janeiro-UFRJ, Rio de Janeiro, RJ, Brazil
}

\section{A R T I C L E I N F O}

\section{Article history:}

Received 9 March 2015

Received in revised form 18 January 2016

Accepted 24 January 2016

Available online 16 February 2016

\section{Keywords:}

Cellulose digestibility

Sugarcane node and internode

Biomass anatomy

Pretreatment

Biomass crystallinity

\begin{abstract}
A B S T R A C T
Sugarcane culm has different types of tissue organization, and its heterogeneity can influence the bagasse quality generated in the sugar/ethanol industry. The heterogeneity of the sugarcane bagasse contributes to the intrinsic recalcitrance of the biomass, impairing its conversion to ethanol. To determine the effects of sugarcane culm heterogeneity, the internode and node fractions were pretreated with acid, alkali, and peroxide. The investigation focused on the change in the fraction morphology, crystallinity, chemical composition, and enzymatic digestibility. Scanning electron microscopy (SEM) revealed different anatomical traits between the node and the internode. Vascular bundles appeared in larger number and diameter in the periphery of both the node and the internode. The internode and node responded differently to the pretreatments, with slight differences in the amount of hemicellulose and lignin removal. Furthermore, the internode was more susceptible to the acid and alkaline pretreatments than the node, generating a material with better digestibility. The fractions pretreated with peroxide showed similar enzymatic digestibility. In SEM images, the internode showed more structural damage after pretreatments than the node fibers. These results provide insight that pretreated sugarcane bagasse has fractions with different enzymatic digestibility related to their anatomy, and that conversion of the entire biomass is not feasible.
\end{abstract}

(C) 2016 Elsevier B.V. All rights reserved.

\section{Introduction}

Renewable fuels derived from lignocellulosic materials are a potential alternative for reducing petrol dependence. Lignocellulosic material (residues) has been considered less expensive than starch and sucrose crops sources (Zheng et al., 2009). However, the lignocellulosic biomass such as sugarcane bagasse is naturally resistant to the conversion process due to its intrinsic chemical, structural, and physicochemical properties (Brienzo et al., 2015). Furthermore, the material heterogeneity contributes to the recalci-

\footnotetext{
* Corresponding author at: Laboratory of Biomass Characterization, Bioenergy Research Institute (IPBEN), São Paulo State University (UNESP), Rio Claro, SP, Brazil.

E-mail address: michelbrienzo@yahoo.com.br (M. Brienzo).
}

trance (Brienzo et al., 2014). These chemical and structural features need to be understood and overcome for successful lignocellulosic material conversion to fuels. A pretreatment step is needed to disassemble the lignocellulosic biomass and make the cellulose accessible to cellulolytic enzymes (Zheng et al., 2009). It is well known that enzymatic hydrolysis of the lignocellulosic biomass is more complex than with starch, for which an industrial-scale approach has been established. The pretreatment and enzymatic hydrolysis of lignocellulosic materials are still challenges for costeffective utilization.

Sugarcane bagasse is the most abundant natural lignocellulosic resource generated as a by-product from the sugar and ethanol industry in tropical countries such as Brazil. The sugarcane bagasse is the sucrose-free culm containing hard rind fibers and soft pith tissue and originates from juice extraction after sugarcane milling 
(Chandel et al., 2012). The culm is formed by a long, solid, cylindrical internode interrupted at intervals by leaf-bearing nodes (Miller et al., 2012). During plant growth, the internode elongates, and the cellulose and lignin content increases while hemicellulose decreases (Lingle and Thomson, 2012). The elongation of the internode varies according to harvest season and cultivar, and normally, the largest (mature) internodes are located at the bottom of the sugarcane plant, and the smallest (immature) one is at the upper part (Sinclair et al., 2005). Sugar content varies along the plant culm height until maturation, the stage in which the sucrose content is established (Nawi et al., 2012). The internode is rich in sucrose-storing parenchyma cells and vascular tissue, and the node is composed of an intercalary meristem or growth ring (Miller et al., 2012), which contains a large amount of vascular bundled cells and a small amount of parenchyma cells. As a lignocellulosic material, the sugarcane bagasse is primarily composed of cellulose, hemicellulose, and lignin, with lower contents of extractives (organic compounds soluble in ethanol/water), ash, and pectin (De Souza et al., 2013). The resistance to utilizing lignocellulosic biomass is reflected in its complex organization of cell wall components and cell arrangement in the different structures and tissues (De Souza et al., 2013).

Invariably, for using biomass (including sugarcane bagasse) in biotechnology approaches, pretreatment is necessary to improve its reactivity, since the enzymatic activity is limited in the untreated materials, making its conversion into fermentable sugar unfeasible (Siqueira et al., 2011). Cellulose microfibrils are embedded in amorphous components, hemicellulose and lignin, creating a complex matrix that impairs the cellulolytic enzyme penetration into the cell wall and compromising their accessibility to the cellulose (Donohoe et al., 2009). Pretreatment enhances the enzyme action over the biomass due to cell wall loosening, lignin removal, or modification, as well as hemicellulose removal and disruption of fiber organization. In addition, the pretreatment aims to produce fibers with high reactivity and avoid generating degradable products that can inhibit the fermentation process (Lynd, 1996). It is desirable for the pretreatment to improve the specific surface area (impacting enzyme accessibility), and to decrease the cellulose crystallinity, polymerization, and protective effect of lignin (Brienzo et al., 2015; Zhu et al., 2008).

Acid pretreatment has been considered efficient for achieving high yields of xylose in the pretreated liquid fraction, since it removes hemicellulose while modifying the lignin structure with lower impact on cellulose (Fengel and Wegener, 1984). The degree of lignin modification and hemicellulose solubilization can be controlled by the pretreatment severity (regarding the combination of acid concentration, temperature, and reaction time). Pretreatments such as alkali $(\mathrm{NaOH})$ and alkaline peroxide have been considered efficient in lignocellulosic structure modification. Alkaline (and peroxide) pretreatments remove lignin and provoke hemicellulose solubilization with a high degree of polymerization (Fengel and Wegener, 1984), increasing cellulose reactivity. Alkaline pretreatment also removes acetyl and uronic acid from the hemicellulose polysaccharides. The removal of lignin and hemicellulose contributes to increasing the internal surface area and decreasing the degree of cellulose polymerization and crystallinity. The peroxide pretreatment has a strong effect on the lignin removal, while the solubilized hemicellulose shows great potential for reuse (Brienzo et al., 2009). Moreover, pretreatment with peroxide improves the digestibility of the cellulose (Monte et al., 2011).

Recently, our group reported the influence of sugarcane tissue heterogeneity on the pretreatment, enzymatic digestibility, and thermal degradation (Brienzo et al., 2014). The work was focused on comparing the epidermis and the response of the internode and node fractions to acid pretreatment. It is reasonable that different plant fractions or tissues such as the node and internode would have diverse responses to the pretreatment strategies due to the cell type and structural arrangement that collectively contribute to the whole anatomical organization of the biomass tissues. Based on that, to understand the chemical and structural traits that contribute to sugarcane recalcitrance in detail, the anatomy, chemical composition, crystallinity, and lignin distribution in the sugarcane internode and node were investigated. In addition, the fractions were pretreated with acid, alkali, and peroxide in order to determine their influence on the enzymatic digestibility of sugarcane bagasse.

\section{Methodology}

\subsection{Sugarcane}

Sugarcane was cultivated over 6 months in the region of Duque de Caxias-Xerém, Rio de Janeiro, Brazil. The sugarcane fractions (node and internode) were separated according to Brienzo et al. (2014). Briefly, sugarcane culms were hand-cut using a stainless-steel knife to remove a 2-mm-thick external fraction containing the epidermis. The epidermis-free culm was subsequently cut in transverse sections by visual identification to obtain the node (the connection point between internodes) and internode (the epidermis-free culm region) fractions. These fractions were mechanically pressed for juice extraction and washed on Soxhlets with water and $95 \%$ ethanol for $6 \mathrm{~h}$ each to remove free sugars. After drying in an oven at $50^{\circ} \mathrm{C}$ for $48 \mathrm{~h}$, the samples were milled and sieved using a size 20 mesh. The material was again subjected to Soxhlet extraction in the same conditions for $6 \mathrm{~h}$. The samples were dried, and the chemical composition was determined according to the Standard Analytical Procedure Methods (LAPs) for biomass developed by the National Renewable Energy Laboratory (NREL, USA) (Sluiter et al., 2010).

\subsection{Pretreatment}

Pretreatment of the node and internode sugarcane bagasse (12.5\% solid loading) was carried out using $4 \mathrm{~g}$ of dry material (DM) as follows: (i) $2.9 \%$ sulfuric acid $\left(\mathrm{m} / \mathrm{v}\right.$ ) at $130{ }^{\circ} \mathrm{C} / 30 \mathrm{~min}$; (ii) $5 \%$ sodium hydroxide (alkaline) ( $\mathrm{m} / \mathrm{v}$ ) at $121^{\circ} \mathrm{C} / 30 \mathrm{~min}$; and (iii) $0.25 \%$ $\mathrm{H}_{2} \mathrm{O}_{2}$ (peroxide) $(\mathrm{m} / \mathrm{v})$ added with $\mathrm{MgSO}_{4} 0.5 \%(\mathrm{~m} / \mathrm{m})$ at $20^{\circ} \mathrm{C} / 4 \mathrm{~h}$ and $\mathrm{pH} 11.6$ (Brienzo et al., 2009). After the reaction was completed, the bottles were submerged in a cold water bath to stop the reaction. Thereafter, the whole slurry was vacuum-filtered into solid and liquid fractions. The obtained pretreated solid (water-insoluble solid-WIS) was washed with $500 \mathrm{~mL}$ of distilled water to reach $\mathrm{pH}$ 5 and then dried at $50^{\circ} \mathrm{C}$ for $48 \mathrm{~h}$. The WIS was used to investigate the effect of the pretreatment on the chemical composition and enzymatic digestibility of cellulose. The liquid fraction was filtered using a $0.22 \mu \mathrm{m}$ filter for HPLC analysis of the sugars.

\subsection{Enzymatic hydrolysis}

Approximately $1 \mathrm{~g}$ of untreated and pretreated sugarcane fractions was transferred to $50 \mathrm{~mL}$ Erlenmeyer flasks containing $20 \mathrm{~mL}$ of $0.05 \mathrm{M}$ citrate buffer at $\mathrm{pH} 4.8$. Shaking was provided by an orbital shaker set at $200 \mathrm{rpm}$ at $50^{\circ} \mathrm{C}$. Cellulase enzyme (Celluclast NS 22118) was added to ensure an activity of $10 \mathrm{FPU} / \mathrm{g}$ of substrate (untreated or pretreated). Cellobiase ( $\beta$-glucosidase; Novozyme 188-NS 22128) was also added at a ratio of 1FPU/3BGU to prevent product inhibition. The total released glucose yields (Biochemistry Analyzer Select YSI 2700 and Shimadzu HPLC) after different hydrolysis reaction times $(2,4,6,8,24,48$, and $72 \mathrm{~h}$ with samples of $0.2 \mathrm{~mL}$ ) were used to calculate the enzymatic digestibility of cel- 
lulose. Experiments were performed in duplicate, and the average is shown.

\subsection{Crystallinity (X-ray)}

X-ray diffraction data of the sugarcane fractions before and after pretreatments were obtained using a SuperNova X-ray Diffractometer (Oxford) with a $\mathrm{Cu}$ tube at an accelerating voltage of $40 \mathrm{kV}$ and a current of $30 \mathrm{~mA}$. The scan was performed at $2 \theta$ angle between $8^{\circ}$ and $28^{\circ}$ with a step size of $0.05^{\circ}$ and a scan rate of $2^{\circ} / \mathrm{min}$. Samples were dried at $50^{\circ} \mathrm{C}$ before analysis. The crystallinity index $(\mathrm{CrI})$ was determined as the percentage of crystalline material in biomass as follows (Eq. 3): $\mathrm{CrI}=100 \times\left[\left(I_{002}-I_{\mathrm{am}}\right) / I_{002}\right]$, where $\mathrm{CrI}$ is the relative degree of crystallinity, $\mathrm{I}_{002}$ is the intensity of the diffraction from the 002 plane at $2 \theta=22.5^{\circ}$, and $I_{\mathrm{am}}$ is the intensity of the background scatter at $2 \theta=18.7^{\circ}$.

\subsection{Scanning electron microscopy (SEM)}

Hand-cut transverse sections of the entire sugarcane culm node and internode were dehydrated in ethanol series and then dried using the $\mathrm{CO}_{2}$ critical point drying method in a Leica EM CPD030. They were then covered by sputtering with a $20 \mathrm{~nm}$ gold layer in a Leica EM SCD500 sputtering device. Secondary electron images were obtained in a Zeiss EVO 40 VP scanning electron microscope operating at $15 \mathrm{kV}$. ATLAS software was used to create large image montages to view the entire sugarcane culm node and internode. Image software was used to count the number of vascular bundles and determine their diameters in SEM images. To carry out these measurements, the node and internode regions were equally subdivided in 3 segments (central, intermediate, and peripheral) with each segment comprising $1 / 3$ of the entire culm (Costa et al., 2013). In order to describe the pretreatment effect on the biomass regions surface, untreated and pretreated materials were washed with deionized water and then dried at $50^{\circ} \mathrm{C}$ for at least $24 \mathrm{~h}$. Secondary electron images of samples were acquired in an FEI Quanta 450 Scanning Electron Microscope operating at an accelerating voltage of $1 \mathrm{kV}$.

\subsection{Lignin distribution and quantification in safranin-stained node and internode}

Hand-cut transverse sections of sugarcane nodes and internodes were stained with $0.1 \%$ Safranin O for $10 \mathrm{~min}$, washed three times in distilled water at $30^{\circ} \mathrm{C}$, and observed in a LEICA TCS-SP5 Confocal Laser Scanning Microscope. Safranin-stained sugarcane sections were excited with a $488 \mathrm{~nm}$ argon laser, and the fluorescence emission and lignin signal were collected in the 581 and $595 \mathrm{~nm}$ spectral regions. Samples were observed using an HCX PLAN APO $20 \times / 0.7$ objective, and a confocal microscopy image series was rendered as maximum projection (2D image from the Z-stack) with an image size of $1024 \times 1024$ pixels. The lignin quantification was conducted by measuring 6 independent vascular bundles per segment of node and internode regions in digital confocal microscopy images. All images were acquired in the same conditions, and the data were evaluated using two-way ANOVA with a 0.05 significance level in statistical tests performed in GraphPad Prism 5 software.

\section{Results and discussion}

\subsection{Anatomical analysis of internode and node}

This study focused on comparison of the fine anatomical characterization of the main regions of sugarcane culm, the node and the internode. Although there are some reports about the structure of the internode region of sugarcane culm (Costa et al., 2013; Siqueira

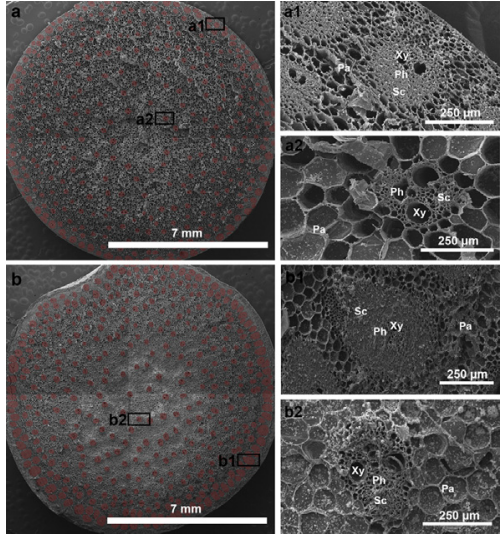

Fig. 1. Transverse section of an individual sugarcane culm internode (a) and node (b) showing the arrangement of vascular bundles. Figs. $1 \mathrm{a}$ and $2 \mathrm{a}$ and Figs. $1 \mathrm{~b}$ and 2 $\mathrm{b}$ are higher-magnification images of selected areas in Fig. 1 and Fig. 2, respectively. The localization of phloem ( $\mathrm{Ph}$ ), xylem (Xy), and parenchyma (Pa) is indicated. Scleremchyma (Sc) are shown in the figures. Vascular bundles in Figs. 1 and 2 were falsely colored in red in order to improve the structure identification. (For interpretation of the references to color in this figure legend, the reader is referred to the web version of this article.)

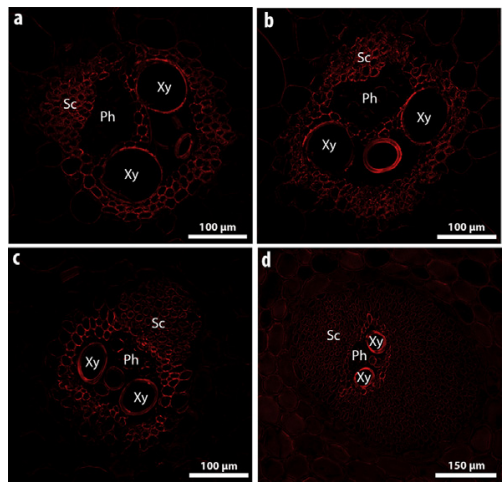

Fig. 2. Lignin distribution in transverse section of vascular bundles of central and peripheral segments in safranin-stained node and internode regions. Red fluorescent signal shows the lignin distribution in the internode center (a) and internode periphery (b), as well as the central (c) and peripheral(d) node segments. The phloem $(\mathrm{Ph})$, xylem $(\mathrm{Xy})$, and parenchyma $(\mathrm{Pa})$ are indicated in the figures. (For interpretation of the references to color in this figure legend, the reader is referred to the web version of this article.)

et al., 2011), complete understanding of the anatomical characteristics of the sugarcane node region, including its vascular bundles, is lacking in the literature. Using SEM image montages, the entire view of cross-sectioned sugarcane culm internode and node was obtained (Fig. 1). This method offered an excellent opportunity to study the fine anatomical features of the sugarcane culm regions, while avoiding speculative data when studying separate parts of biomass regions.

SEM images of individual node and internode readily revealed their diverse anatomical arrangements. From the periphery to the center, the sugarcane culm is formed by the epidermis, cortex, and ground tissue (Moore, 1987; Sant'Anna et al., 2013, 2014). Beneath the epidermis, the sugarcane tissue is organized in stiff vascular bundles embedded in soft parenchymatous tissue. Vascular bundles have the highest degree of recalcitrance in the inner part of grass culm due to the cell wall diversity and high lignin concentration (Jung and Casler, 2006). Morphologically, sugarcane vascular bundles comprise the xylem, phloem, and sclerenchyma, as observed in SEM images (Figs. $1 \mathrm{a}, 2 \mathrm{a}, 1 \mathrm{~b}$, and $2 \mathrm{~b}$ ). The sclerenchyma surrounds the vascular bundles and was composed of thick-walled highly lignified sclerenchyma fibers, forming a 
protective sheath. In peripheral segments of the node and internode, vascular bundles were spaced with a small distance between each other and were embedded in small-sized parenchyma cells. In contrast, in the central segments, vascular bundles were well spaced and embedded in parenchyma tissue composed of large cells (Fig. 1a and b). A similar pattern was reported for maize stem tissues (Jung and Casler, 2006).

Morphological analysis by SEM revealed significant anatomical differences in the dimensions of the sclerenchyma associated with vascular bundles regarding their relative position. The peripheral vascular bundles of the node (Fig. 1b) and the internode (Fig. 1a) had heavier sclerenchymatous sheaths compared with the central vascular bundles (Fig. $2 \mathrm{a}$ and b). In the light of microscopic view reported by Jung and Casler (2006), similar diversity in the amount of layers of sclerenchyma cells in the vascular bundle of internodes was observed in maize cross-section. On the other hand, the diameter of vessels was negatively correlated with the number of sclerenchyma cells, i.e., vascular bundles with larger sclerenchyma sheath had smaller vessel diameter, and vice versa. Moreover, SEM images of the node and internode regions showed that vascular bundles were arranged in either circular or elliptical shapes (Figs. $1 \mathrm{a}, 2 \mathrm{a}, 1 \mathrm{~b}$, and $2 \mathrm{~b}$ ). These results clearly show that the anatomy of vascular bundles is determined by their location in the tissue regions, as indicated by Costa et al. (2013).

\subsubsection{Distribution of vascular bundles in sugarcane tissues}

The vascular bundles were spread all over the node and internode culm bellow the epidermis. Clearly, the number of vascular bundles found in the node and internode regions was not constant, and they were unequally distributed across the tissues. These results are in agreement with those reported to sugarcane internode (Costa et al., 2013). It was estimated that the total amount of vascular bundles was larger in the node region $(n=386)$ compared with the internode region $(n=355)$. The physiological meaning of this difference is of great interest for understanding the recalcitrance, but it is beyond the scope of this study.

The quantitative distribution of the central, intermediate, and peripheral vascular bundles was investigated. The vascular bundle distribution pattern was similar in both the internode and node, where the number of vascular bundles increased from the center toward to the peripheral segments, as reviewed by Moore (1987). The number of peripheral vascular bundles in the internode region was found to be 234, while the numbers of intermediate and central vascular bundles decreased to 93 and 38, respectively. Costa et al. (2013) also described a progressive increase in the number of vascular bundles from the central to peripheral region of internode of sugarcane. In the case of the node region, there were 233 peripheral vascular bundles, 122 intermediate, and 60 central. In comparison, the decrease in the number of vascular bundles between the peripheral and central segments of the node region was smaller than in the internode region.

The minimum number of vascular bundles in sugarcane culm was found in the central region of the internode. Since the recalcitrance of the biomass is influenced by the abundance of vascular bundles, these findings indicate that the recalcitrance of culm segments increases from the center to the periphery in both the internode and node. A previous report of vascular bundle distribution exclusively in hybrid sugarcane internode tissue showed that the number and size of vascular bundles increased from the central to the peripheral segment (Costa et al., 2013). The authors showed that the vascular bundle organization was positively correlated with increasing resistance to enzymatic digestibility of untreated samples.

The diameter of vascular bundles was estimated in both the internode and node regions. The mean diameter measurement depicted in Table 1 shows that vascular bundles at the periph- ery of the node region were the largest structure found in the sugarcane culm. Furthermore, there was no variance in the mean diameter between the peripheral, intermediate, and central internode vascular bundles, as well as with the central and intermediate vascular bundles of the node. The peripheral vascular bundles of the node (Fig. 1b) clearly had the highest number of sclerenchyma cells, which may explain the largest vascular diameter found. The mean diameter of the vascular structure in the peripheral segment of the node was $329.72 \mu \mathrm{m}$, while that in the same segment in the internode region was $263.80 \mu \mathrm{m}$. In the intermediate segment of node, the mean diameter was $244.72 \mu \mathrm{m}$, and in the intermediate segment of the internode, it was $228.37 \mu \mathrm{m}$. In the central segments, the mean diameters found in vascular bundles of the node and internode were $245.66 \mu \mathrm{m}$ and $225.66 \mu \mathrm{m}$, respectively. Diameter measurement data showed that the maximum diameter found in the analyzed sugarcane culm was $453.69 \mu \mathrm{m}$ at the peripheral segment of the node region, and the minimum was $158.34 \mu \mathrm{m}$ at the central segment of the internode region. The peripheral fraction showed larger vascular bundles in both the node and the internode. It is important to mention that while the peripheral segment of the node presented larger vascular bundles, the number of structures was higher at the peripheral region of the internode. However, the diameter results suggest that the periphery of the node could be more recalcitrant than the internode.

The anatomical traits of vascular bundles change across the sugarcane tissues (Sant'Anna et al., 2013, 2014) and seem to be related to local recalcitrance (Costa et al., 2013). The results here presented strongly suggest that the variance of vascular bundle morphology and distribution observed in the node and internode regions has a key effect on the recalcitrance of sugarcane culm. The distribution of vascular bundles seems to be responsible for local stiffness in the plant tissue due to its specific properties, such as structure and lignin concentration (Pollet et al., 2008). The analyses of the vascular bundles in the node and internode regions of sugarcane provide an excellent model of morphological parameters to determine the intrinsic recalcitrance of biomass tissues.

It is worth to mention that the present findings are based on just one sugarcane type and may represent one of many different types of morphological organization in different sugarcane species, which are influenced by the growth conditions and age. Our observations provide new insights into the organization of the more recalcitrant element, the vascular bundles, and their anatomical organization in the node compared to the internode culm regions.

\subsection{Lignin distribution and quantification in vascular bundles of node and internode segments}

Another key factor affecting the recalcitrance of biomass is the lignification of plant cell walls. Lignin is an important component of plant cell walls that has been intensely investigated in lignocelullosic material because of its function as a barrier to biomass enzymatic hydrolysis (Brienzo et al., 2015; Kong et al., 1992; Masarin et al., 2011; Sant'Anna et al., 2014). It is well known that the cell-wall lignin content negatively correlates with biomass degradability. Moreover, the lignin composition and distribution influence the biomass recalcitrance (Siqueira et al., 2011). In the present work, the distribution of lignin was revealed by staining sugarcane nodes and internodes with safranin (Fig. 2).

The confocal microscopy images allowed for the comparative localization of lignin in lignified structures of the node and internode (Fig. 2). In addition, the relative amounts of lignin in different vascular bundle cell types could be directly visualized, and nonhomogneity in the lignin distribution was evident (De Souza and Sant'Anna, 2012; Sant'Anna et al., 2013). Examining the red fluorescence signal of lignin in central and peripheral segments of the sugarcane node and internode, it was noticed that vascular bun- 
Table 1

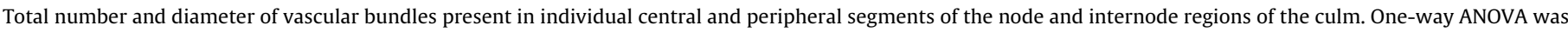
used for data comparison. Values with different letters ( $\mathrm{a}$ or $\mathrm{b}$ ) are significantly different at $p \leq 0.05$.

\begin{tabular}{|c|c|c|c|c|c|}
\hline Culm region & Region segments & Number of VB & Minimum diameter $(\mu \mathrm{m})$ & Maximun diameter $(\mu \mathrm{m})$ & VB's mean diameter $(\mu \mathrm{m})$ \\
\hline \multirow[t]{4}{*}{ Node } & Center & 31 & 195.94 & 302.41 & $242.58^{a}$ \\
\hline & Intermediate & 122 & 201.92 & 308.75 & $244.72^{\mathrm{a}}$ \\
\hline & Periphery & 233 & 268.41 & 453.69 & $329.72^{\mathrm{b}}$ \\
\hline & Total & 386 & na & na & na \\
\hline \multirow[t]{4}{*}{ Internode } & Center & 19 & 158.34 & 245.67 & $224.83^{\mathrm{a}}$ \\
\hline & Intermediate & 93 & 165.42 & 280.69 & $228.37^{a}$ \\
\hline & Periphery & 243 & 250.39 & 410.16 & $263.80^{\mathrm{a}}$ \\
\hline & Total & 355 & na & na & na \\
\hline
\end{tabular}

VB: vascular bundle; na: not applied.

dles were structurally composed of high and low lignified tissues. In comparison, for all vascular bundles analyzed in the node and internode segments, the sclerenchyma surrounding the vascular bundles were the most heavily stained walls, demonstrating that sclerenchyma fibers contained more lignin than other vascular tissue. In addition, in the peripheral and central vascular bundles of the node and internode, intense red lignin signals were found in the vessels and xylem walls, but the phloem walls were lightly stained, indicating less lignification (Bond et al., 2008; Sant'Anna et al., 2013).

In the sugarcane species analyzed in this work, the direct analysis of the vascular bundles showed no significant variation in the red lignin signal in peripheral (16.012 AU) and central (16.674 AU) vascular bundles in the node region. No variation was also found in the peripheral (15.477 AU) and central (17.173 AU) vascular bundles of the internode region. These findings indicate that there was no gradient of lignification from the central to the peripheral vascular bundles. According to Waters (2009), the intensity value of a pixel in fluorescence microscopy is related to the signal from the fluorophores present in a given sample area.

Interestingly, the pattern of lignification in vascular bundles did not follow the increasing layer of the sclerenchyma sheath. As seen in SEM images (Fig. 1), the peripheral node and internode bundles had more sclerenchyma fibers organized in more layers of cells. This layer of fibers decreased from the peripheral to the central vascular bundles. From the lignin signal observed in confocal microscopy, it was clear that the lignification remained unaltered according to the local position and structure of the vascular bundles. This result indicates that the recalcitrance of the central and peripheral segments of the node and internode is mostly related to the morphology, distribution, and frequency of the vascular bundles.

Based on the findings, it can be concluded that while there was structural variance in the vascular bundles in the central and peripheral segments of the node and internode regions, the pattern of lignification remained unaltered. However, the lignin concentration did not tend to increase from the center to the periphery of culm vascular bundles, at least in the sugarcane type investigated. The distinct anatomical traits and lignin distribution found in the internode and node fractions of sugarcane culm could be key factors in their response to pretreatment and enzymatic hydrolysis. To confirm this hypothesis, the internode and node were pretreated with acid, alkaline, and peroxide, and then subjected to enzymatic hydrolysis as follows.

\subsection{Chemical composition and pretreatment effect}

The chemical composition analysis revealed a slight differential concentration of cellulose, hemicellulose, and lignin in the sugarcane internode and node. While the internode was composed of $39.58 \%$ cellulose, $27.87 \%$ hemicelluloses (xylan, arabinan, and acetyl groups), and $19.88 \%$ lignin, the node contained $41.17 \%$ cellulose, 25.58\% total hemicelluloses, and 21.32\% lignin (Table 2).
Importantly, the chemical analysis showed that the lignin content was similar in the internode and node, supporting the data acquired by fluorescence quantification (Table 2).

Most of the hemicellulose was removed from the node and internode by acid pretreatment (Table 2) (Brienzo et al., 2014). The alkaline and peroxide pretreatment removed less hemicellulose compared to acid pretreatment from both the internode and node. However, when subjected to such pretreatments, the internode was more susceptible to hemicellulose removal than the node. The residual hemicellulose contents after alkaline pretreatment were $11.78 \%$ and $12.87 \%$ in the internode and node, and after peroxide pretreatment, they were $16.78 \%$ and $18.20 \%$, respectively. The higher amount of residual hemicellulose in the node region indicates higher recalcitrance compared to the internode. The node is richer in vascular bundles than the internode (Table 1). The difference in hemicellulose removal is small, but it reflects the different material characteristics, such as heterogeneity and consequent recalcitrance (Brienzo et al., 2014).

The acid pretreatment enriched the lignin content, while after alkaline and peroxide pretreatment, typical lignin removal was observed in the both internode and node (Monte et al., 2011; Moutta et al., 2014). The residual lignin content was higher for the node than the internode in the pretreated samples. Lignin was enriched by 6.64 percentage points (pp) in the internode and by $8.33 \mathrm{pp}$ in the node subjected to acid pretreatment. Alkaline pretreatment was more effective in lignin removal from both the internode and node than peroxide pretreatment. The residual lignin contents after alkaline pretreatment were $5.22 \%$ and $7.79 \%$, in the internode and node, and after peroxide pretreatment, they were $8.51 \%$ and $8.63 \%$, respectively. Alkaline pretreatment promotes lignin removal by saponification of the intermolecular ester bonds of hemicellulose and lignin, while peroxide pretreatment depolymerizes the lignin, fragmenting the structure into low fraction compounds (Gould, 1985). The more lignified vascular bundle cells that are present at higher amounts in the node fraction (Fig. 1) can be the key to the different recalcitrance response of the fractions. In fact, vascular bundles support the structural features of the tissue.

The peroxide removal of hemicellulose from the internode and node had similar levels when industrial sugarcane bagasse was used (from sugarcane crushed for juice extraction with no fraction separation) (Brienzo et al., 2009). However, a slight enrichment in cellulose and a decrease in lignin fraction were found in comparison to industrial sugarcane bagasse (Monte et al., 2011). The acid removed hemicellulose entirely, while it increased the cellulose fraction and enriched the lignin content in the pretreated internode and node compared with industrial sugarcane bagasse using same experimental conditions (Moutta et al., 2014). The results suggest that the internode and node isolated from sugarcane culm respond differently to pretreatment technologies. The differences observed in the internode and node fractions are a consequence of chemical composition (Table 2), lignin distribution, and cell and tissue 
Table 2

Chemical composition and crystallinity index of untreated, acid, alkaline, and peroxide pretreated sugarcane culm internode and node fractions.

\begin{tabular}{|c|c|c|c|c|}
\hline Sample & Cellulose (\%) & Hemicellulose (\%) & Lignin (\%) & $\operatorname{CrI}(\%)$ \\
\hline Internode & $39.58(2.37)$ & $27.87(0.91)$ & $19.88(0.66)$ & $46.61(0.48)$ \\
\hline Node & $41.17(1.56)$ & $25.58(0.99)$ & $21.32(0.45)$ & $44.70(2.30)$ \\
\hline Internode- $\mathrm{H}_{2} \mathrm{SO}_{4}$ & $60.41(0.40)$ & - & $26.52(0.23)$ & $56.28(2.14)$ \\
\hline Node- $\mathrm{H}_{2} \mathrm{SO}_{4}$ & $60.44(2.34)$ & - & $29.65(0.24)$ & $53.63(0.86)$ \\
\hline Internode- $\mathrm{H}_{2} \mathrm{O}_{2}$ & $56.44(1.20)$ & $16.78(0.95)$ & $8.51(2.70)$ & $52.63(2.70)$ \\
\hline Node- $\mathrm{H}_{2} \mathrm{O}_{2}$ & $49.48(3.14)$ & $18.20(1.01)$ & $8.63(1.25)$ & $56.73(2.07)$ \\
\hline Internode- $\mathrm{NaOH}$ & $69.58(0.01)$ & $11.78(0.01)$ & $5.22(0.07)$ & $63.07(3.31)$ \\
\hline Node-NaOH & $67.64(4.57)$ & $12.87(0.14)$ & 7.79 (1.29) & $61.84(3.61)$ \\
\hline
\end{tabular}

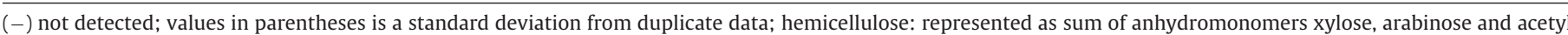
group. Lignin total: represented as sum of soluble and insoluble lignin. CrI: crystallinity index.

organization (Fig. 1). Furthermore, in a rough comparison, these fractions respond differently from the industrial bagasse, where there is an influence of the fraction content and more complex material heterogeneity (Brienzo et al., 2014; Moutta et al., 2014).

\subsection{Enzymatic hydrolysis}

The untreated and pretreated sugarcane fractions were subjected to enzymatic hydrolysis for digestibility comparison. The internode and node fractions showed glucose yields of 26.89 and $20.46 \%$, respectively, after $72 \mathrm{~h}$ of enzymatic hydrolysis (Fig. 2). Comparing the untreated internode with the node fraction in terms of digestibility, we found a higher resistance of the node to the enzymatic action, as expected. The anatomical organization of the node fraction makes the tissue more resistant to pretreatment and makes the cellulose fibers less accessible to enzyme action. The heterogeneity and different digestibility can be also found in different regions of the untreated internode, which was fractionated from the inside to the outside and named as the pith, interface, rind, and epidermis. These fractions had glucose yields of $86,35,10$, and $5 \%$, respectively (Costa et al., 2013).

Acid and alkali pretreated fractions were more susceptible to enzymatic hydrolysis compared to the peroxide pretreated fractions (Fig. 2a-c). The acid pretreated internode and node had glucose yields of 73 and $57.7 \%$, respectively (Fig. 2a). The alkaline pretreated internode and node had glucose yields of 70.3 and $58.3 \%$, respectively (Fig. 2 b), while the peroxide pretreated internode and node had glucose yields of 50.8 and $51.8 \%$, respectively (Fig. 2c). These results showed that tissue with low lignin content is less recalcitrant (Várnai et al., 2014), but the pretreatment can overcome recalcitrant tissue and improve its enzymatic digestibility.

Considering that the chemical compositions of the internode and node are similar, the difference in the pretreatment response and enzymatic digestibility could be attributed to the morphological and physicochemical properties of the fractions. The substrate properties that affect the enzyme action are the heterogeneous morphology/composition, cellulose crystallinity, degree of polymerization, and cellulose accessibility (Brienzo et al., 2015; Hallac and Ragauskas, 2011; Himmel et al., 2007). Moreover, the anatomical influence on the material recalcitrance was clear in the present study, which was attributed to the vascular bundles and lignin distribution (Table 1 and Fig. 1).

The glucose yields after enzymatic hydrolysis were higher for the internode and node pretreated with acid for a short reaction time in the stage characterized as fast hydrolysis (Arantes and Saddler, 2011). In this stage, it is clear that the glucose rate of the acid pretreated fraction (Fig. 2a) is higher than with other pretreatment types such as alkaline (Fig. 2b) and peroxide (Fig. 2c). The fast increase in hydrolysis glucose yield within a short time indicates that the acid pretreated fractions had a more severe effect than other pretreatments, loosening the barriers to enzyme action such as the lignin and hemicellulose protective effects. In fact, for acid pretreated fractions, the chemical composition revealed no hemicellulose content (Table 2). The lignin is not removed in acid conditions, but its structure changes, which probably reduces the protective effect or physical barrier increasing the cellulose accessibility (Brienzo et al., 2015).

\subsection{Biomass crystallinity index}

The crystallinity index $(\mathrm{CrI})$ of the untreated internode and node were 46.61 and $44.7 \%$, respectively (Table 2). This range of crystallinity values is similar to those found for industrial sugarcane bagasse (48\%) (Brienzo et al., 2015; Corrales et al., 2012), as well as previously reported values for node and internode fractions of $42.78 \%$ and $45.82 \%$, respectively (Brienzo et al., 2014). The close crystallinity index of the internode and node was most likely due to the similar chemical composition based on cellulose content in these fractions (Table 2).

Acid pretreatment increased the biomass $\mathrm{CrI}$ as an effect of hemicellulose removal, while alkali and peroxide pretreatment increased biomass CrI mainly by lignin removal (Table 2). Hemicellulose solubilization after acid pretreatment increases the cellulose proportion in the material (crystalline component) (Table 2). The same effect on the crystallinity index was observed for alkali and peroxide pretreated materials. Alkali and peroxide pretreatments solubilize hemicellulose with high degree of polymerization, which are soluble in alkali conditions (Brienzo et al., 2009). The alkali pretreatment is recognized to provoke swelling of the cellulose fibers (Sobue et al., 1939), which could decrease the crystallinity index by changing the organization from crystalline to amorphous. Moreover, the amorphous regions of cellulose are more efficiently enzymatically hydrolyzed than the crystalline regions, with direct impact on the initial conversion rate (Chang and Holtzapple, 2000). In spite of the swelling of cellulose fibers during the alkali pretreatment, the subsequent drying step could collapse the structure and increase the crystallinity of the cellulose, reversing the swelling effect. In summary, the alkali pretreatment increases the biomass CrI by hemicellulose and lignin removal, and it decreases the crystallinity index by fiber swelling. Moreover, the removal of amorphous components could be superimposed with the effect of fiber swelling, resulting in a global increase in the crystallinity index of the biomass.

\subsection{Surface change of untreated and pretreated samples}

The untreated internode and node showed fiber regions with slightly affected structures, which may be a result of the milling process (Fig. 4). The acid pretreated internode was more affected than the node. The fiber surface of the internode showed more damage and fragmentation of the cell wall (Fig. 4). An acid pretreatment with higher severity ( 10 and $20 \%$ acid concentration) revealed 
a)

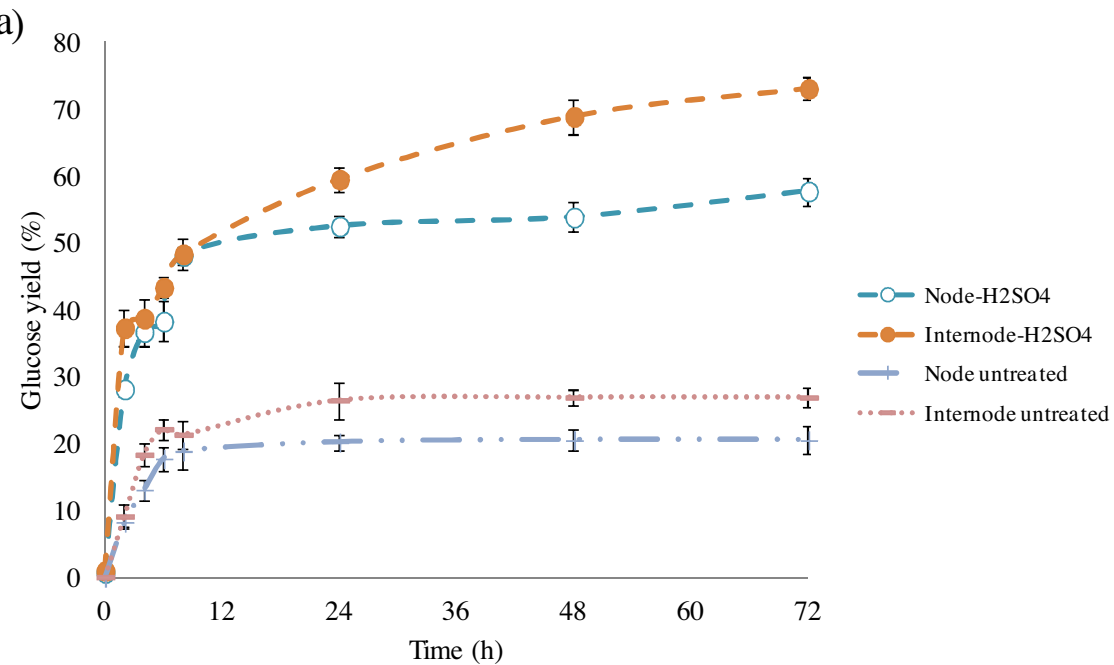

b)
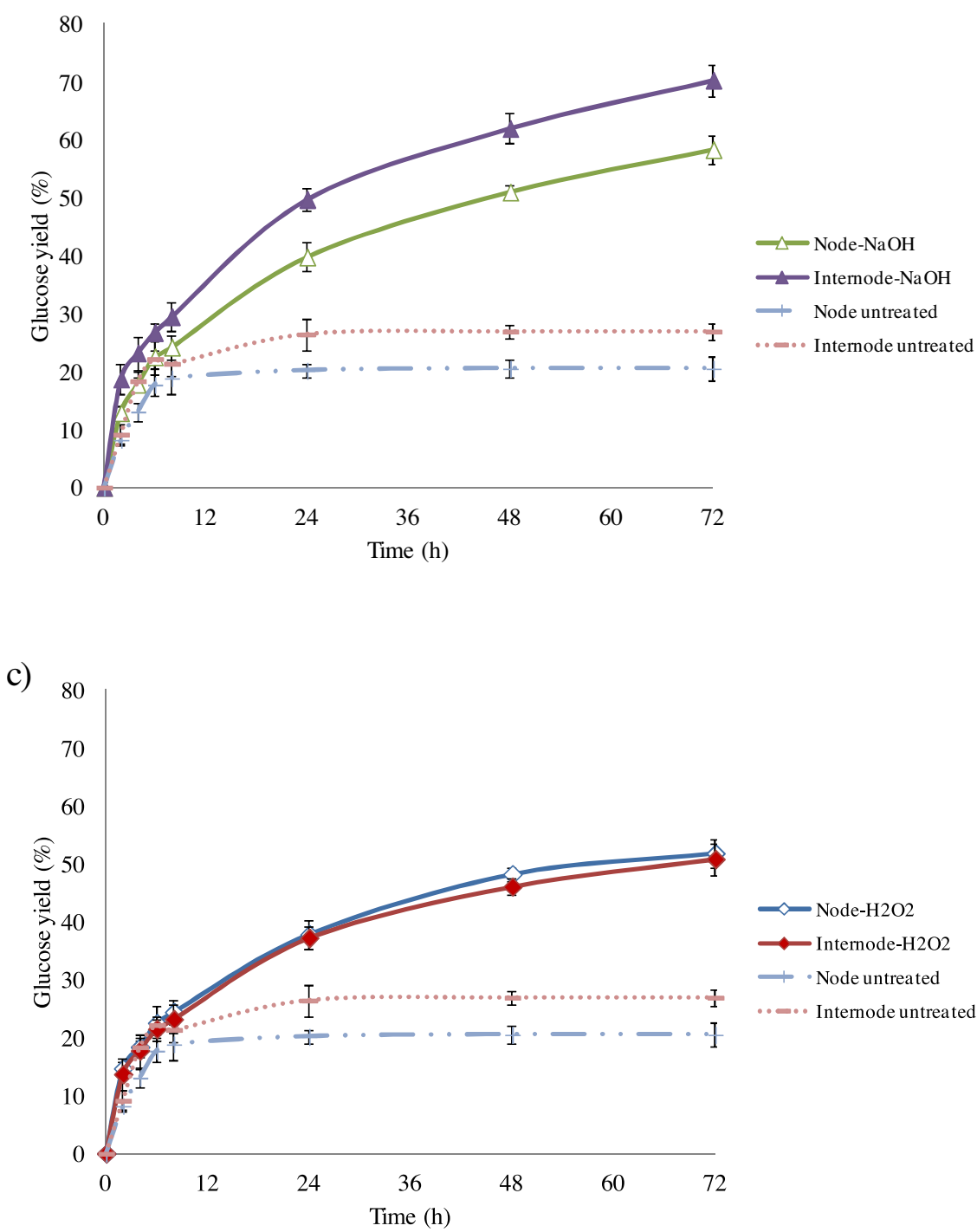

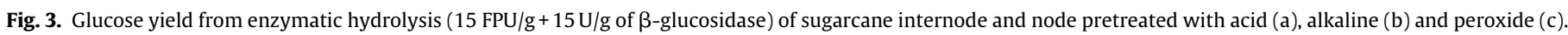

significant differences in the degradation of the internode and node fractions (Brienzo et al., 2014). Moreover, the acid pretreated internode was more susceptible to the enzymatic hydrolysis, with higher glucose yield than the node hydrolysis (Fig. 3). The alkaline pretreatment provoked similar degradation of the internode and node according to the SEM images (Fig. 4). However, the enzymatic 


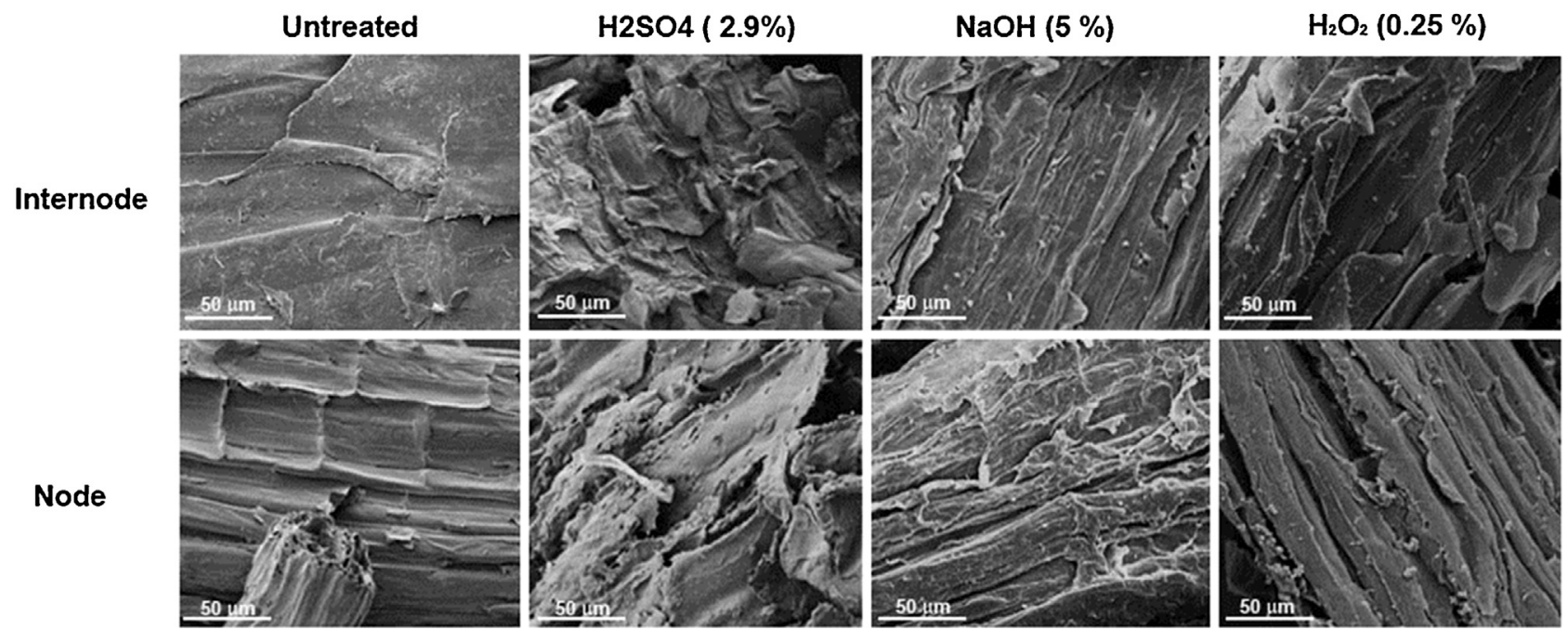

Fig. 4. Scanning electron microscopy images of untreated, acid, alkaline, and peroxide pretreated sugarcane internode and node.

hydrolysis of the internode released more glucose than the node (Fig. 3b). The alkaline pretreatment removes the hemicellulose and lignin fraction, which was similar in the internode and node fractions (Table 2). Moreover, this pretreatment changed several physicochemical properties, improving the material digestibility.

The peroxide pretreatment resulted in node and internode materials with similar enzymatic hydrolysis digestibility (Fig. 3c). The node had more recalcitrant tissue. This was likely due to the amount and morphological aspects of the vascular bundles (Fig. 1), which are highly lignified plant structures (Sant'Anna et al., 2013). However, the peroxide pretreatment provoked morphological alteration of the node structure, improving its digestibility to the same level observed with the internode (Fig. 3c). The peroxide pretreatment removes hemicellulose and lignin, provoking oxidation of the aromatic structures of the lignin (Liu, 2003). Comparatively, the glucose yield released by enzymatic hydrolysis was lower for the peroxide pretreated materials than for the alkaline and acid pretreated materials.

\section{Conclusion}

Internode and node fractions showed different lignin distributions in vascular bundles under microscopy analysis, which is a function of the nature of cells and their organization in these fractions. However, it was clear that there are different morphology and distribution of the vascular bundles in the culm node and internode. This anatomical discrepancy seems to be directly linked to the recalcitrance of the node in comparison to the internode. The chemical composition of the internode and node revealed similar contents of the main components, e.g., cellulose, hemicellulose, and lignin, which is in agreement with the microscopy quantification. The internode was less recalcitrant than the node to the pretreatments applied, with better response to acid than alkaline and peroxide pretreatments, resulting in higher enzymatic hydrolysis yield. In agreement with enzymatic digestibility, the internode showed a fiber surface that was more damaged by all pretreatments, while peroxide provoked similar fiber change in SEM. It could be suggested that the heterogeneity of the sugarcane fractions (internode and node) associated with the vascular bundle content and size is a relevant factor in the recalcitrance and need for an optimized pretreatment to efficiently convert cellulosic biomass.

\section{Acknowledgments}

The authors are thankful to the Brazilian Innovation Agency (FINEP), the Brazilian Council for Research and Development (CNPq), and National Institute of Metrology, Quality, and Technology (Prometro grant number 550105/2012-8) for financial support.

\section{References}

Arantes, V., Saddler, J., 2011. Cellulose accessibility limits the effectiveness of minimum cellulase loading on the efficient hydrolysis of pretreated lignocellulosic substrates. Biotechnol. Biofuels 4, 3 .

Bond, L., Donaldson, L., Hill, S., Hitchcock, K., 2008. Safranine fluorescent staining of wood cell walls. Biotech. Histochem. 83, 161-171.

Brienzo, M., Siqueira, A.F. Milagres, A.M.F. 2009. Search for optimum conditions of sugarcane bagasse hemicellulose extraction. Biochem. Eng. J. 46, 199-204.

Brienzo, M., Ferreira, S., Vicentim, M.P., Souza, W., SantAnna, C., 2014. Comparison study on the biomass recalcitrance of different tissue fractions of sugarcane culm. Bioenergy Res. 7, 1454-1465.

Brienzo, M., Tyhoda, L., Benjamin, Y., Görgens, J., 2015. Relationship between physicochemical properties and enzymatic hydrolysis of sugarcane bagasse varieties for bioethanol production. New Biotechnol. 32, 253-262.

Chandel, A.K., Silva, S.S., Carvalho, W., Singh, O.V., 2012. Sugarcane bagasse and leaves: foreseeable biomass of biofuel and bio-products. J. Chem. Technol. Biotechnol. 87, 11-20.

Chang, V.S., Holtzapple, M.T., 2000. Fundamental factors affecting biomass enzymatic reactivity. Appl. Biochem. Biotechnol. 84-86, 5-37.

Corrales, R.C.N.R., Mendes, F.M.T., Perrone, C.C., Sant'Anna, C., Souza, W., Abud, Y., Bom, E.P.S., Ferreira-Leitão, V., 2012. Structural evaluation of sugar cane

bagasse steam pretreated in the presence of $\mathrm{CO}_{2}$ and $\mathrm{SO}_{2}$. Biotechnol. Biofuels 5,36

Costa, T.H.F., Masarin, F., Bonifácio, T.O., Milagres, A.M.F., Ferraz, A., 2013. The enzymatic recalcitrance of internodes of sugar cane hybrids with contrasting lignin contents. Ind. Crop Prod. 51, 202-211.

De Souza, W., Sant'Anna, C., 2012. Microscopy as a tool to follow deconstruction of lignocellulosic biomass. In: Méndez-Vilas, Antonio (Ed.), Current Microscopy Contributions to Advances in Science and Technology. Formatex Research Center, pp. 639-645.

De Souza, A.P., Leite, D.C.C., Pattathil, S., Hahn, M.G., Buckeridge, M.S., 2013. Composition and structure of sugarcane cell wall polysaccharides: Implications for second-generation bioethanol production. Bioenergy Res. 6, 564-579.

Donohoe, B.S., Selig, M.J., Viamajala, S., Vinzant, T.B., Adney, W.S., Himmel, M.E., 2009. Detecting cellulase penetration into corn stover cell walls by immuno-electron microscopy. Biotechnol. Bioeng. 103, 480-489.

Fengel, D., Wegener, G., 1984. Wood: Chemistry, Ultrastructure, Reactions. Walter de Gruyter, Berlin, New York

Gould, J.M., 1985. Studies on the mechanism of alkaline peroxide delignification of agricultural residues. Biotechnol. Bioeng. 27, 225-231.

Hallac, B.B., Ragauskas, A.J., 2011. Analyzing cellulose degree of polymerization and its relevancy to cellulosic ethanol. Biofuels Bioprod. Biorefin. 5, 215-225.

Himmel, M.E., Ding, S.Y., Johnson, D.K., Adney, W.S., Nimlos, M.R., Brady, J.W., Foust, T.D., 2007. Biomass recalcitrance: engineering plants and enzymes for biofuels production. Science 315, 804-807. 
Jung, H.G., Casler, M.D., 2006. Maize stem tissues: cell wall concentration and composition during development. Crop Sci. 46, 1793-1800.

Kong, F.R., Engler, C.R., Soltes, E.J., 1992. Effects of cell-wall acetate, xylan backbone, and lignin on enzymatic-hydrolysis of aspen wood. Appl. Biochem. Biotechnol. 34-35, 23-35.

Lingle, S.E., Thomson, J.L., 2012. Sugar internode composition during crop development. Bioenergy Res. 5, 168-178.

Liu, S., 2003. Chemical kinetics of alkaline peroxide brightening of mechanical pulps. Chem. Eng. Sci. 58, 2229-2244.

Lynd, L.R., 1996. Overview and evaluation of fuel ethanol from cellulosic biomass: technology economics, the environment, and policy. Annu. Rev. Energy Environ. 21, 403-465.

Masarin, F., Gurpilhares, D.B., Baffa, D.C.F., Barbosa, M.H.P., Carvalho, W., Ferraz, A. Milagres, A.M.F., 2011. Chemical composition and enzymatic digestibility of sugarcane selected for varied lignin content. Biotechnol. Biofuels 4, 55 .

Miller J.D., Gilbert R.A., Odero D.C., 2012. Sugarcane botany: a brief view. Document is SS-AGR-234, one of a series of the Agronomy Department, Florida Cooperative Extension Service, Institute of Food and Agricultural Sciences, University of Florida. Access on July of 2014, http://edis.ifas.ufl.edu/sc034

Monte, J.R., Brienzo, M., Milagres, A.M.F., 2011. Utilization of pineapple stem juice to enhance enzyme-hydrolytic efficiency for sugarcane bagasse after an optimized pre-treatment with alkaline peroxide. Appl. Energy 88, 403-408.

Moore, P.H., 1987. Anatomy and morphology. In: Heinz, D.J. (Ed.), Sugarcane Improvement Through Breeding. Elsevier, Amsterdam, pp. 273-311.

Moutta, R.O., Ferreira-Leitão, V.S., Bom, E.P.S., 2014. Enzymatic hydrolysis of sugarcane bagasse and straw mixtures pretreated with diluted acid. Biocatal. Biotransform. 32, 93-100.

Nawi, N.M., Chen, G., Jensen, T., Baillie, C., 2012. Prediction of sugar content along the height of sugarcane internodes using VisNIR. In: International Conference of Agricultural Engineering (CIGR-AgEng 2012), Valencia, Spain.
Sant'Anna, C., Costa, L.T., Abud, Y., Biancatto, L., Miguens, F.C., De Souza, W., 2013. Sugarcane cell wall structure and lignin distribution investigated by confocal and electron microscopy. Microsc. Res. Tech. 76, 829-834.

Sant'Anna, C., De Souza, W., Brienzo, M., 2014. The influence of the heterogeneity, physicochemical and structural properties on the recalcitrance and conversion of sugarcane bagasse. In: Sugarcane: Production, Consumption and Agricultural Management Systems. Eleanore Webb, pp. 1-34.

Sinclair, T.R., Gilbert, R.A., Perdomo, R.E., Shined, J.M., Powell, G., Montes, G., 2005. Volume of individual internodes of sugarcane stalks. Field Crops Res. 91, 207-215.

Siqueira, G., Milagres, A.M.F., Carvalho, W., Koch, G., Ferraz, A., 2011. Topochemical distribution of lignin and hydroxycinnamic acids in sugarcane cell walls and its correlation with the enzymatic hydrolysis of polysaccharides. Biotechnol. Biofuels 4, 7.

Sluiter, A., Hames, B., Ruiz, R., Scarlata, C., Sluiter, J., Templeton, D., Crocker, D., 2010. Determination of structural carbohydrates and lignin in biomass. Lab. Anal. Proced.

Sobue, H., Kiessig, H., Hess, K., 1939. The cellulose-sodium hydroxide water system as a function of the temperature. Z. Physik. Chem. B 43, 309-328.

Waters, J.C., 2009. Accuracy and precision in quantitative fluorescence microscopy J. Cell Biol. 185, 1135-1148.

Várnai, A., Costa, T.H.F., Faulds, C.B., Milagres, A.M.F., Siika-aho, M., Ferraz, A., 2014 Effects of enzymatic removal of plant cell wall acylation (acetylation, p-coumaroylation, and feruloylation) on accessibility of cellulose and xylan in natural (non-pretreated) sugar cane fractions. Biotechnol. Biofuels 7, 153.

Zheng, Y., Pan, Z., Zhang, R., 2009. Overview of biomass pretreatment for cellulosic ethanol production. Int. J. Agric. Biol. Eng. 2, 51-68.

Zhu, L., Dwyer, J.P.O., Chang, V.S., 2008. Structural features affecting biomass enzymatic digestibility. Bioresour. Technol. 99, 3817-3828. 